IN PRESS AT JOURNAL OF EXPERIMENTAL SOCIAL PSYCHOLOGY

This paper is not the copy of record and may not exactly replicate the final, authoritative version of the article. Please do not copy or cite without authors' permission. The final article will be available, upon publication, via its DOI.

\title{
When Getting More Makes Groups Seem Worth Less: Negotiating a 'Better' Deal in Prisoner Swaps Can Ironically Signal Low Self-Regard and Engender Disrespect
}

\author{
Andrea G. Dittmann ${ }^{1 *}$, Nour Kteily ${ }^{2}$, \& Emile Bruneau ${ }^{3}$ \\ ${ }^{1}$ Emory University, Goizueta Business School, Atlanta, GA 30322 \\ ${ }^{2}$ Northwestern University, Kellogg School of Management, Evanston, IL, 60208 \\ ${ }^{3}$ University of Pennsylvania, Philadelphia, PA 19104
}

${ }^{*}$ Corresponding author

Email: andrea.dittmann@emory.edu

Supplemental Online Material is available on the OSF at the following link: https://osf.io/fw3g4/?view_only=ac8404abe12e49bf89e232d11946914e 


\begin{abstract}
Prisoner exchanges between groups in conflict are often a first step towards peace. As with bargaining more generally, groups presumably try to get the best deal possible. But when exchanging human lives, can getting 'more' make your group seem worth less? Building on research on signals of self-regard at the interpersonal level, we consider whether certain behaviors - even strategically beneficial ones - can diminish perceptions of the esteem in which a group holds itself, with consequences for the respect and treatment it is afforded. Across six preregistered experiments (total $N=5,060$ ), we find that groups that negotiate a 'better deal' (e.g., getting multiple prisoners back in return for releasing only one outgroup prisoner; negotiating down the 'price' for retrieving a single prisoner) are ironically seen as placing less value on themselves, and, as a consequence, are respected less and prescribed worse treatment. We observe these results in real-world and in artificial contexts, and whether perceivers belong to the outgroup in conflict or are neutral third-party observers. A seventh study, focused on the decision to pursue or eschew a risky rescue mission (with negative expected value of lives saved) expands beyond the prisoner swap context, highlighting that our results are one manifestation of a general tendency for perceivers to intuit a group's self-regard from its actions. Our work suggests that, when deciding between various courses of action, it would behoove groups to consider the ways in which their actions subtly communicate how highly they value themselves.
\end{abstract}

Keywords: self-worth; social perception; intergroup dynamics; intergroup conflict; respect 
In 2011, Israel freed 1,027 Palestinian prisoners in exchange for just one Israeli soldier (Wilkinson, 2011). Uneven trades such as these are not uncommon and are typically celebrated by the group receiving more prisoners (al-Mughrabi \& Heller, 2011). On its face, this is sensible: Why shouldn't a group revel in securing a 1000:1 trade from its more powerful counterpart? But are there hidden costs to getting more for less? By accepting a deal that values just one Israeli at over 1,000 Palestinians, the Palestinian side might indirectly communicate that the worth of their citizens' lives pales in comparison to those of the Israeli side. Here, we consider seemingly advantageous behaviors that groups may pursue on account of self-interest in the context of intergroup conflict, but that we propose may ironically communicate to others that they have low self-regard. We examine how these strategic behaviors are interpreted both by audiences who belong to the conflicting outgroup and third-party observers, in both real-world and artificial group contexts. In addition to its practical consequences for intergroup conflict, our work also suggests a novel route by which perceivers might come to make attributions about the worthiness of other groups (and how much they should be respected): subtle cues their strategic actions may unintentionally send about how much regard they have for themselves.

\section{Prisoner Swaps: Signals of a Group's Self-Worth?}

Understanding the psychology underlying prisoner swaps (and how they come to affect perceivers' evaluations of groups) is important given the consequential role they play in conflict resolution. Prisoner swaps often serve as a "first step" toward reconciliation for warring nations that might not otherwise be willing to engage with one another diplomatically (Pillar, 2014). For example, in a conflict situation that has been, until recently, considered a stalemate, Ukraine and Russia have begun to engage in prisoner exchanges, which are viewed as initial "confidencebuilding steps," (Kramer, 2019). In a similar vein, the prisoner exchange conducted between the 
Obama administration and Iran in 2016 has been described as a motivator that encouraged Iran to make progress toward compliance with the terms of the nuclear deal. Indeed, Obama himself described the swap as reflecting, "our willingness to engage with Iran to advance our mutual interests" (Korte, 2016). Given that these swaps often represent an initial opening or step toward reconciliation, and tend to be highly publicized, they have the power to meaningful shape the attributions and attitudes of perceivers (Baskin, 2020), including by shaping processes such as trust and respect that are themselves critical components of the pathway towards sustainable peace (Darwall, 1977; Galeotti, 2010; Ramsbotham, Miall \& Woodhouse, 2011; Wolf, 2011). Reflecting their significance to conflict and its resolution, prisoner swaps date at least as far back as the late 700s (i.e., to the times of Arab-Byzantine conflict; Rotman, 2009) and have featured regularly across a range of distinct conflicts over the last half-century alone. For example, aside from its aforementioned swap with the Palestinians in 2011, Israel has exchanged prisoners on multiple occasions with Hamas and Hezbollah; the United States and the Soviet Union regularly exchanged captured soldiers and spies during the Cold War; seven imprisoned Houthi rebels in Yemen were exchanged for a Saudi prisoner in 2019 (Al-Haj, 2019); and, as recently as 2020, the United States and Iran concluded a prisoner swap exchanging an IranianAmerican doctor held by the U.S. for a U.S. Navy veteran who had been detained by Iran (Reuters, 2020). Of particular interest to the current investigation, sometimes these swaps involve unequal or even grossly unequal transfers, as with the 2011 Israeli/Palestinian trade and the Saudi/Houthi exchange. Other times the swaps involve one-to-one transfers, as in the 1962 exchange between the U.S. and the Soviet Union (Wicker, 1962) or the most recent U.S.-Iranian exchange. 
As reflected in these widely varying ratios, prisoner swaps are one of only a small handful of contexts in which groups essentially "price" their members' lives (Yeini, 2018). In this investigation, we sought to understand whether the ratios involved in these swapsparticularly salient to perceivers, who learn about the broad contours of trades but aren't privy to the intricacies of the diplomacy process - shape perceptions of groups' self-worth (e.g., Baskin, 2020; Larson, 1988). We reasoned that witnessing an unequal (versus equal) prisoner swap-a deal more like the 1000:1 Israel-Palestinian trade in 2011 than the 1:1 U.S.-Soviet exchange in 1962 - would lead perceivers to infer that the group accepting a ratio involving getting more ingroup members back in exchange for fewer outgroup prisoners placed less value on the lives of the members of their group (and thus had lower self-regard). In particular, we reasoned that, in lopsided trades, perceivers would conclude that the group who 'spent' less in terms of prisoners released versus reclaimed sees ingroup lives as less valuable than does the group who 'spent' more. In contrast, we theorize that perceivers are more likely to infer that groups place high value on themselves if the ratio of the trade is more equal and less lopsided. ${ }^{1}$

Beyond the relative ratio of lives involved, groups involved in prisoner exchanges might also indirectly signal their self-regard in other ways. We additionally consider, for example, perceptions of a group depending on how they respond to the financial cost proposed by the

\footnotetext{
${ }^{1}$ Of note, this inference would likely be less relevant if perceivers were explicitly made aware that the specific individuals involved have different objective 'values,' as in other types of exchanges like athlete trades in professional sports. In those cases, there is generally a wide consensus that a player from Team A with extremely high athletic qualities is 'worth' multiple players from Team B with more average qualities. Thus, a deal that appears lopsided in terms of the number of people involved may nevertheless be seen as balanced for both sides (Drinen, 2008), and there is no valid basis for inferring that Team B generally places less value on its own group than Team A (indeed, both sides may well agree that some other individual player currently on Team B has athletic value equivalent to multiple Team A members). However, in the context of prisoner exchanges, unless given explicit information to the contrary, the general public has no reason to believe that the individual prisoners themselves have different 'value'. As such, a reasonable conclusion to draw from trades with lopsided numbers is that the groups value each life of a group member differently, with the group getting 'more' in exchange for less having lower selfregard.
} 
outgroup for the return of an ingroup prisoner. In particular, we compare perceptions of a group that strategically negotiates down the price requested (thereby securing the same outcome on more favorable financial terms) to perceptions of a group that agrees to pay the initial price. Again, we reason that despite getting a 'better deal', insisting on paying less for an ingroup prisoner might indirectly communicate that the group places less value on itself. ${ }^{2}$

\section{Signals of Self-Regard}

That the terms of a prisoner swap might signal a group's self-regard to perceivers builds on and extends a large literature on attributional processes in the interpersonal domain. Indeed, the actions in which target individuals engage signal a variety of personal attributes to perceivers, in turn influencing how perceivers see and treat these targets (Anderson, Brion, Moore, \& Kennedy, 2012; Lennon, Johnson, \& Schulz, 1999; Macrae \& Quadflieg, 2010; Schlenker \& Leary, 1982; Wojciszke, Bazinska, \& Jaworski, 1998). Indeed, individuals’ behavior can sometimes be interpreted as reflecting low self-regard even when this isn't consistent with how individuals see themselves. For example, research on objectification suggests that, regardless of individuals' actual self-views, certain cues (e.g., clothing choices, body art) can lead perceivers to infer that targets have low self-regard (Holland \& Haslam, 2013; McElroy, Summers, \& Moore, 2014; Swami \& Furnham, 2007). In one study, when perceivers evaluated photos of female athletes dressed provocatively, they rated them as having significantly less self-respect than when they were dressed in sport-appropriate outfits (Gurung \& Chrouser, 2007). Relatedly, qualitative research on waitresses working in sexuallyobjectifying environments has documented that, while the waitresses themselves often reported

\footnotetext{
${ }^{2}$ It would perhaps be unsurprising if perceivers came to believe that groups that passively failed to stand up for themselves had low self-regard. But in a conservative test, we consider cases in which perceptions of low self-worth might emerge - ironically - even when a group effortfully and assertively engages in a course of action in pursuit of strategic self-interest.
} 
having a high level of self-esteem and confidence, they were nonetheless objectified by customers, who (inaccurately) inferred from their workplace that these waitresses saw themselves as objects (Moffitt \& Szymanski, 2011). Translating this attributional framework to the intergroup domain, we consider, for the first time, how actions by groups can signal their level of self-regard, and as discussed below, thereby shape perceivers' subsequent attitudes and behavioral intentions towards them. Moreover, although our work focuses primarily on how these processes play out in the prisoner swap context, we begin to explore (including in our final study) how the theoretical link between group behavior and perceived self-regard may have broader relevance for intergroup relations.

\section{Consequences of Low Self-Regard}

Why might it matter if perceivers conclude that groups have low worth on the basis of how they think these groups see themselves? We reason that perceivers will afford and treat groups with respect based in part on how much they see those groups as valuing themselves. Indeed, research on self-fulfilling prophecies in the interpersonal domain demonstrates that people treat targets in ways that are consistent with their own perceptions of those targets, even when those perceptions are inaccurate (Stukas \& Snyder, 2016). For example, regardless of students' actual ability level, teachers tend to treat students who they perceive to have low ability in ways that align with that perception - by calling on them less or spending less time with them (Madon, Willard, Guyll, \& Scherr, 2011).

At the intergroup level, evidence suggests that groups seen as lacking worth are treated as such, facing exclusion, mistreatment, or aggression (Andrighetto, Riva, Gabbiadino, \& Volpato, 2016; Haslam, 2006; Kteily, Hodson, \& Bruneau, 2016; Kteily, Bruneau, Waytz, \& Cotterill, 2015; Opotow, 1990). Building on these findings, we similarly consider the consequences of 
being perceived to have low self-worth, while focusing on a different input to these perceptions. Existing intergroup research has examined how egocentric or ethnocentric biases shape how much worth perceivers ascribe to their own group versus outgroups (Epley, Keysar, Van Boven, \& Gilovich, 2004; Pratto \& Glasford, 2008; Pratto, Glasford, \& Hegarty, 2006; see also Haslam, 2006). Other work has also looked at how we ascribe other groups higher or lower worth depending on their instrumental goals (Orehek \& Weaverling, 2017), the nature of the intergroup relationship (e.g., "how they see us"; Andrighetto, Riva, Gabbiadino, \& Volpato, 2016; Kteily, Hodson, \& Bruneau, 2016), or features of these groups' behavior towards others (Bruneau \& Kteily, 2017; Leidner et al., 2013). In contrast to this previous work, here we consider how judgments of low group worth can emerge based on subtle signals these groups' actions might implicitly send about how highly they value themselves.

We focused on outcomes previously identified as critical to the reconciliation process by both scholars and practitioners of international relations. In particular, we focused on respect, as operationalized both in terms of intergroup attitudes and behavioral intentions (e.g., Friedrichs, 2016; Wolf, 2011). International relations scholars have theorized that earning the respect of other groups can promote sympathy and trust, which can ultimately contribute to cooperation (Gaertner et al., 2000; Somerville, 2009). Speaking to the centrality of achieving mutual respect to the process of moving from intergroup conflict toward cooperation, developing respect for the other side was critical to the resolution of the 'Troubles' in Northern Ireland. Indeed, the fundamental element of the Belfast Agreement, viewed as the first step toward the ultimate peace settlement, was assuring respect and recognition of both sides in the conflict (Allison, 2012; Belfast Telegraph, 2012). Indeed, to this day, the Northern Ireland government conducts an annual survey, one of the key outcomes of which is a "Respect Index" that tracks how respected 
citizens feel, and is explicitly broken out by religious group to compare the felt respect of Catholics and Protestants (Northern Ireland Executive, 2020). Similarly, in New Zealand, shifting national mindsets to afford the Maori people greater respect has been viewed as a critical step in repairing relations between Maori and non-indigenous New Zealanders, and New Zealand is now often held up as an exemplar to other nations for how to effectively repair relations between indigenous and non-indigenous peoples (Morris, 2014). Beyond measures of perceivers' attitudinal respect, we also look at perceivers' reported willingness to engage in intergroup behaviors that reflect their levels of (dis)respect: examining both whether perceivers will recommend more aggressive and unethical treatment of groups perceived to have lower selfregard.

\section{The role of threat and power}

In sum, then, we propose that negotiating a strategically favorable prisoner swap (i.e., receiving more ingroup prisoners in exchange for less outgroup prisoners; negotiating down the financial cost of an ingroup prisoner) will, ironically, lead observers to see a group as having lower self-regard, and therefore afford them less respect. At the same time, in assessing the link between strategically beneficial behavior and disrespect, we sought to control for other mechanisms that might account for the link beyond perceptions of self-regard. In particular, we focused on perceptions of threat and power. For example, groups who push to arrive at a strategically favorable lopsided prisoner trade might be viewed and treated negatively not because of how their behavior shapes perceptions of their self-regard, but because pushing for a favorable deal makes them appear excessively assertive or threatening (e.g., driving a tough bargain; Wildschut, Pinter, Vevea, \& Insko, 2003; Golec de Zavala, Cichocka, Eidelson, \& Jayawickreme, 2009; Kteily, Saguy, Sidanius \& Taylor, 2013). Similarly, asking for more in 
negotiation might make a group seem more powerful (Fiske \& Dépret, 1996; Sachdev \&

Bourhis, 1987), thereby rendering it more risky to disrespect them. By statistically accounting for these potential links connecting strategically beneficial behavior and downstream (dis)respect, we can be more confident in any distinct role of perceptions of self-regard.

Notably, a group's actions in a prisoner swap might, in principle, be judged differently by an opponent in conflict (who might be motivated to make negative attributions) than by a neutral third party. Still, we reasoned, however, that the terms of the prisoners swaps we considered should lead even 'disinterested' observers to infer different levels of self-regard. To examine this, we included studies with both outgroup and third-party perceivers. Similarly, notwithstanding the added realism real-world conflicts offer, perceivers might bring to mind preexisting beliefs and motivations when considering behavior in the context of real-world disputes. To examine the generalizability of our theorizing, we therefore considered the extent to which our effects held both in real-world and artificial group contexts.

\section{The Current Research}

Across seven experiments, we test how groups' actions in prisoner swaps can send subtle signals about how highly they value themselves, suggesting a novel input into how individuals might make inferences about group worth. We focused specifically on strategically-beneficial actions that a group (presumably) effortfully pursued in the context of prisoner swaps that, ironically, might nevertheless signal low self-worth to perceivers. Specifically, we examined whether: (a) groups negotiating a 'better' deal in prisoner swaps would ironically be seen as having lower self-regard, (b) groups perceived to have lower self-regard as a result of their actions would be granted less respect and treated worse, and (c) perceived group self-regard would serve as a mechanism linking group actions to respect for and ascribed treatment toward 
the group. Perceivers belonging to the conflicting outgroup (Studies 1A-2A, 3A-B) or third-party observers (Studies 2B, 4) read about a group's action in intergroup conflict, and then evaluated the group's perceived self-regard, reported their respect for the group, and indicated how they thought the group should be treated in the future. Our final study (Study 4) examined whether the theoretical processes we examine generalize outside the specific context of prisoner swaps by looking at the decision to pursue or eschew a risky rescue mission (with negative expected value of lives saved). We controlled throughout for perceptions of the group's threateningness and power (the sole exception being Study 1A). We report all measures, manipulations, and exclusions in these studies here and in the supplementary materials. We provide the raw data sets and syntax for analyses, available on the Open Science Framework at the following link: https://osf.io/tafeg/?view_only=288036073dde459d841adbf0b8f5dce9.

\section{Studies 1A-B: Equal vs. Unequal Prisoner Swap}

In Study 1A, we began by examining prisoner swaps in the context of the U.S.-Iran conflict. We predicted that although an unequal (vs. equal) prisoner swap where Iran received more prisoners from the U.S. would be strategically beneficial to Iran, by implicitly implying Iran's acceptance of a ratio in which each Iranian life was worth less than each American life, it would lead U.S. perceivers to see Iran as having lower-self regard and respect them less.

In Study 1B, we sought to replicate and extend our effects from Study 1A to an artificial intergroup context to ensure effects generalized beyond the U.S.-Iranian context (about which participants likely had pre-existing attitudes). In Study 1B, we also controlled for two key potential alternative explanations: perceptions of outgroup threat and power (noted above). In the main text, we focus on the critical theorized path through self-regard, but all results come from 
models that include perceptions of power and threat as alternative mediators. The specific results regarding these paths through threat and power for each study are included in the SOM.

\section{Method}

Study 1A Participants. We preregistered our study on aspredicted.org (http://aspredicted.org/blind.php? $\mathrm{x}=\mathrm{r} 956 \mathrm{xt}$; we made two minor deviations from our preregistration, namely: (a) analyzing the absolute scores of the dependent measures instead of difference scores, for ease of interpretation, and (b) conducting indirect effects tests that were not pre-registered and as such, are exploratory in nature). We aimed for a sample size approximately double that of a similar initial pilot study we conducted (see SOM), for a total sample of 450 participants. Thus, we recruited a sample of 506 U.S. residents from Amazon's MTurk, expecting to have to exclude some individuals who failed attention checks (which required that participants recall the details of the manipulation that they read, across two multiple choice questions). After excluding those individuals who failed at least one of two attention check items as outlined in our preregistration, we were left with a sample of 409 participants $\left(M_{\text {age }}=35.83\right.$, $S D=10.87 ; 46.5 \%$ male; 320 Whites/European Americans; 22 Asian/Asian Americans; 18 Latino/Hispanic Americans; 36 Black/African Americans; seven Biracial/Mixed Race, three Middle Eastern/Arab American, two Native American, one Other). A sensitivity analysis suggested we were adequately powered to detect a small effect of $d=0.28$ at $80 \%$ power.

Study 1B Participants. We preregistered our study on OSF (https://osf.io/6gvc4/?view_only=9df13b4eceb645d6ba0f311548ad7ef4). Based on the results of Study 1A, we expected a small effect, and aimed for a sample size similar to that of Study 1A, for a final sample of approximately 400. Thus, we recruited a sample of 501 U.S. residents from Amazon's MTurk, expecting to exclude some individuals who failed attention checks. After 
excluding those individuals who failed at least one of two attention check items, we were left with a sample of 410 participants $\left(M_{\text {age }}=36.48, S D=11.26 ; 49 \%\right.$ female; 316 Whites/European Americans; 28 Asian/Asian Americans; 22 Latino/Hispanic Americans; 32 Black/African Americans; 8 Biracial/Mixed Race, 1 Middle Eastern/Arab American, 2 Other). A sensitivity analysis suggested we were adequately powered to detect a small effect of $d=0.28$ at $80 \%$ power.

Studies 1A-B Design and procedure. Participants were recruited to complete a 10minute study about 'Current Events' in exchange for \$1. Upon entering the study, participants were randomly assigned to one of two conditions: an equal or an unequal swap condition. Participants in the equal swap condition read an article about a prisoner swap between the U.S. and Iran that was purportedly being considered by both sides, in which one U.S. prisoner of war would be exchanged for one Iranian prisoner of war. Participants in the unequal deal condition read an identical article, except that the ratio of the trade was said to be one U.S. prisoner of war for 20 Iranian prisoners of war. The text of the manipulation, which was presented in the form of a purportedly real article from a major national newspaper, read as follows: "Discussions have begun between Tehran and Washington about a possible prisoner swap, with initial reports suggesting that the deal being considered would free one American from Iranian prisons, with one Iranian prisoner of war [20 Iranian prisoners of war] dating from the time of the U.S.'s presence in Iran being released in exchange" (See SOM for full article text). The design and procedure of Study 1B were identical to that of Study 1A except that the prisoner exchange was described as between Group A and Group B rather than the U.S. and Iran. In both conditions, participants were instructed to imagine that they were a member of Group A. After reading through the article, participants completed our survey before being debriefed and paid. 
Study 1A Measures. We include a complete list of all measures, the order in which they were presented, and the inter-correlations among all variables for all studies in SOM. In evaluating our hypotheses, we focused primarily on direct evaluations of their self-regard. However, we also considered (across studies) the extent to which perceivers believed the group to be committed to its members as another, more indirect, way to evaluate perceivers' sense of groups' self-regard. While results for these items are generally similar to the results presented in the main text, for the sake of brevity, we provide the specific results for these measures in SOM.

Perceived self-worth. To assess perceived self-worth, we asked three separate items about the perceived self-worth of the Iranian people. One item assessed whether participants felt that Iran believed itself to be of equal worth relative to the U.S.: "Iranians, as a people, think that Iranians and Americans have equal worth." A second item assessed whether participants thought Iran believed they were worth much more than the U.S.: "Iranians, as a people, think that Iranians are worth much more than Americans." A final item assessed whether participants thought Iranians believed that they were worth less than the U.S.: "Iranians, as a people, think that Iranians are worth much less than Americans." All items were assessed on a $1=$ Strongly disagree to $7=$ Strongly agree scale. We focus here on Americans' perceptions of Iranians' selfworth (see SOM for information on Americans' perceptions of their own group).

Respect for Iranian outgroup. We asked participants how much they respected the Iranian outgroup using a 3-item measure (e.g., "I respect the Iranian side," "The Iranian side is honorable" and "The Iranian side is admirable"; $1=$ Strongly disagree, $7=$ Strongly agree; $\alpha=$ $.96)$.

Study 1B Measures. The measures were highly similar to that of Study 1A, except that they were asked as they pertained to Group A and Group B. Beyond our (modified) measures of 
perceived self-worth, we employed one new indicator to capture perceptions of the value the outgroup placed on itself: perceptions of the outgroup's dignity.

Perceived self-worth. To assess perceptions of the self-worth of Group B, we asked four items. The items were: “Group B, as a people, think that Group A and Group B have equal worth"; "Group B rejects the idea that they are worth any less than Group A"; "Group B, as a people, think that members of Group B are worth much less than members of Group A" (reversecoded); and "Group B has high self-worth". All items were assessed on a 1 = Strongly disagree to $7=$ Strongly agree scale $(\alpha=.71)$, with lower scores indicating lower perceptions of the outgroup's (i.e., Group B) self-worth.

Perceived dignity. To assess perceptions of Group B's dignity, we asked three items. The items were: "Group B has a lot of dignity,"; "Group B believes it should be held in high regard,"; and "Group B is a proud people." All items were assessed on a $1=$ Strongly disagree to $7=$ Strongly agree scale $(\alpha=.85)$.

Respect. We measured respect for Group B with the same items as in Study 1A $(\alpha=.97)$.

\section{Covariates.}

Perceived threat. To assess perceptions of how threatening Group B was, we asked three items adapted from previous research (Kteily et al., 2013). The items were: "Group B seemed to pose a significant threat to Group A," "I found Group B to be aggressive," and "Group B is being too pushy in its attempts to get what it wants." All items were assessed on a $1=$ Strongly disagree to $7=$ Strongly agree scale $(\alpha=.91)$.

Perceived power. To assess perceptions of Group B's power, we asked four items adapted from previous research (Kteily et al., 2013). The items were: "In general, when you think of Group A and Group B, who do you think has more power?"; "Which side benefits most 
from the status quo between the two sides?"; "Which side in the conflict has a more desirable current state of affairs?" and "Which side has more to lose if the situation continues as it is for a long period of time?" All items were assessed on a $1=$ Definitely Group $A$ to $7=$ Definitely Group $B$ scale $(\alpha=.72)$, such that higher numbers indicate perceiving that Group B is more powerful.

\section{Study 1A Results}

Perceived self-worth. In line with our predictions, Study 1A participants in the unequal deal condition were significantly less likely to perceive that Iranians saw themselves as being of equal worth to Americans $(M=2.99, S D=1.56)$ than participants in the equal deal condition $(M$ $=3.71, S D=1.81), F(1,407)=18.85, p<.001, \eta_{p}^{2}=.044$. Moreover, being in the unequal deal condition lead Americans to perceive that Iranians felt that their lives were worth less than Americans (unequal condition: $M=2.47, S D=1.77$; equal condition: $M=2.06, S D=1.30) ; F(1$, $\left.407)=7.01, p=.008, \eta_{p}^{2}=.017\right)$. We observed no evidence that participants in the unequal deal condition perceived that Iranians felt their lives were worth more than those of Americans (unequal condition: $M=4.54, S D=1.84$; equal condition: $M=4.42, S D=1.78), F(1,407)=$ $\left.0.45, p=.502, \eta_{p}^{2}=.001\right)$. In sum, witnessing an unequal trade in which Iranians received more prisoners back than Americans led participants to think that Iranians had lower overall self-worth than those who witnessed an equal trade. Of note, this pattern of results occurred despite the fact that participants perceived that this deal was strategically more favorable to Iran than the U.S. (see SOM for more information on participants' overall evaluation of the deal).

Respect for Iranian outgroup. We observed a significant difference by condition in the extent to which participants respected the Iranian outgroup. As predicted, participants respected 
the Iranian outgroup significantly less in the unequal $(M=3.09, S D=1.54)$ compared to the equal deal condition $(M=4.07, S D=1.64), F(1,407)=38.45, p<.001, \eta_{p}^{2}=.09$.

\section{Study 1B Results}

We found main effects of experimental condition on each of the covariates (new to Study 1B): In the unequal (vs. equal) condition, participants were marginally more likely to perceive that Group B was powerful $\left(M_{\text {unequal }}=3.97, S D=1.76\right.$ vs. $\left.M_{\text {equal }}=3.71, S D=0.94\right), F(1,408)=$ $3.83, p=.051, \eta_{p}^{2}=.01$, and significantly more likely to perceive Group B as threatening $\left(M_{\text {unequal }}=4.07, S D=1.60\right.$ vs. $\left.M_{\text {equal }}=3.69, S D=1.36\right), F(1,408)=6.69, p=.010, \eta_{p}^{2}=.02$.

We report all results using ANCOVAs that tested the effect of our experimental condition on the key outcome variables while controlling for perceived threat and power; thus, all means presented in this and subsequent studies reflect adjusted means and standard errors. All conclusions are equivalent when these covariates are excluded (see SOM for results excluding covariates in this and all subsequent studies).

Perceived self-worth. Replicating Study 1A, participants in the unequal deal condition perceived that Group B had significantly lower self-worth $(M=3.84, S E=.08)$ than participants in the equal deal condition $(M=5.13, S E=.08), F(1,408)=129.98, p<.001, \eta_{p}^{2}=.24$.

Perceived dignity. Similar to the results regarding perceived self-worth, participants in the unequal swap condition perceived that the Group B outgroup had significantly less dignity $(M=4.33, S E=.09)$ relative to those who witnessed an equal swap $(M=5.16, S E=.08), F(1$, $408)=51.28, p<.001, \eta_{p}^{2}=.11$

Respect for group. As in Study 1A, participants in the unequal condition respected the Group B outgroup significantly less $(M=3.76, S E=.09)$ than those in the equal condition $(M=$ 4.38, $S E=.09), F(1,408)=24.24, p<.001, \eta_{p}^{2}=.06$. 
Studies 1A-B indirect effects. We used the PROCESS macro (Hayes, 2017) in SPSS to test our hypothesized indirect effects model (see Figure 1). Specifically, we examined whether the ratio of the prisoner swap (i.e., equal vs. unequal) would predict perceptions of Iranians' equal self-worth, which in turn would predict how much respect perceivers granted the Iranian outgroup. ${ }^{3}$ As predicted, we observed a significant indirect effect from condition to respect for the Iranian outgroup via perceptions of Iranians' self-worth (indirect effect $=-0.307,95 \%$ CI [0.481, -0.165]) such that the lower respect Americans afforded Iranians in the unequal (vs. equal) deal condition was linked to their reduced perceptions of Iranians' self-worth. Taken togetherand bearing in mind the limitations of correlational indirect effects analyses (Fiedler, Harris, \& Schott, 2018) — these analyses provide initial support for our overall theoretical model (wherein groups afford a focal group less respect when it behaves in ways that they interpret as signaling low self-regard).

In Study 1B, we again used the PROCESS macro in SPSS to test our indirect effects model. Specifically, as in Study 1A, we sought to examine whether the ratio of the prisoner swap (i.e., equal vs. unequal) would predict perceptions of Group B's self-regard (indexed here using perceived self-worth), which in turn would predict how much respect perceivers' granted Group B. To examine this, we tested whether there was an indirect effect from the prisoner swap condition to respect for Group B via the perceived self-worth of Group B. Following our preregistration, given the strong positive correlation between perceived self-worth and dignity $(r$ $=.71$ ), we only include one of these two constructs (i.e., self-worth) in the indirect effects model to minimize multicollinearity. We follow this approach for this and all subsequent studies (see

\footnotetext{
${ }^{3}$ We included the perception of equal self-worth item as our key predictor in the indirect effect model because this item best captured our primary theoretical interest in examining the effect perceiving that Iran has equal self-worth. However, the results are equivalent when controlling for responses to both the "worth more" and "worth less" items (see SOM for details).
} 
SOM for indirect effects including perceived dignity in place of self-worth). We also included perceived threat and power as potential mediators to control for any possible effects of condition on outgroup respect through these constructs. ${ }^{4}$ As predicted, and replicating Study 1A, we observed significant indirect effects from condition to respect via perceptions of self-worth ($0.407 ; 95 \%$ CI $[-0.568,-0.266])$.

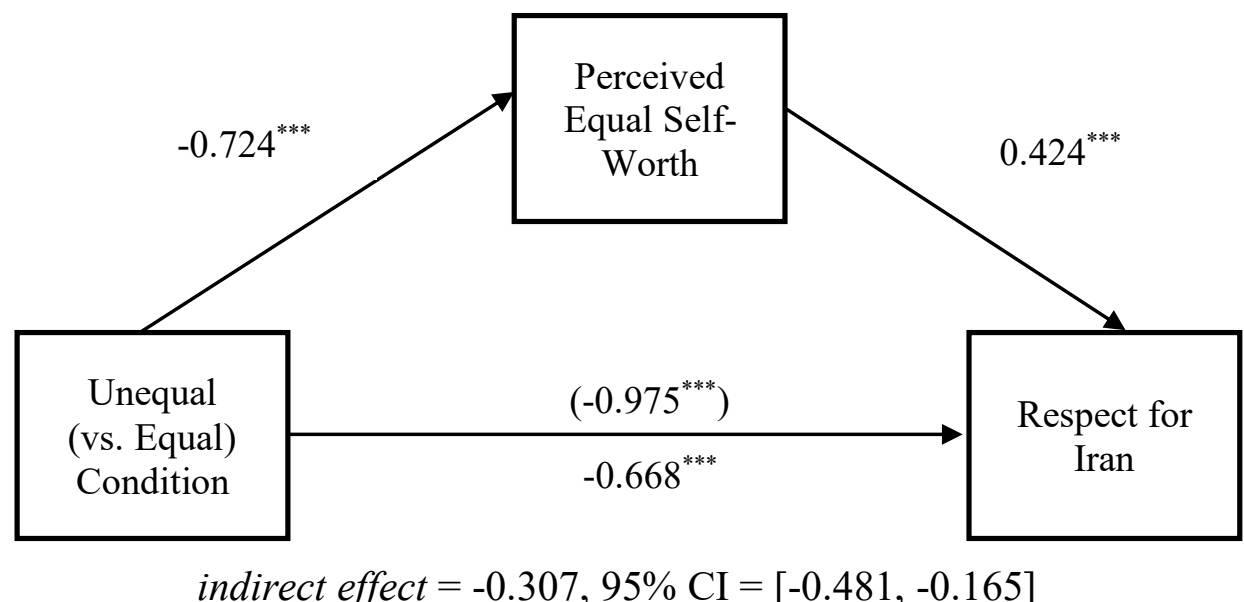

Figure 1. Mediation model in Study 1A. Note. ${ }^{* * *} p<.001$.

I akell lugellel, aciuss iwo slumes, leaully auvul ullequal (vs. equal) pissullel swaps in

which an outgroup (either Iran or Group B) received more prisoners relative to the ingroup

(either the U.S. or Group A) decreased participants' perceptions that the outgroup had high selfworth and dignity. Of note, this pattern of results emerged, ironically, despite the fact that in the unequal swap condition, the outgroup had actually secured the return of more ingroup prisoners than in the equal condition. Importantly, lower perceptions of the outgroup's self-regard helped

\footnotetext{
${ }^{4}$ Of note, including threat and power as alternative mediators means that we are controlling for them when we consider the effect of perceived self-worth on the outcome measure (i.e., the 'b' path) but not when considering the effect of condition on perceived self-worth (i.e., the 'a' path). We included threat and power as alternative mediators to provide more information about their role in mediating the effects of condition on outgroup respect. However, we note that results are equivalent if we simply include perceived threat and power as covariates when examining both the ' $a$ ' and ' $b$ ' paths (see SOM for all indirect effects through perceived threat and power).
} 
to account for the lower respect participants granted the outgroup in the unequal deal condition, and, in Study 1B, did so even after accounting for how threatening and powerful the outgroup seemed.

\section{Studies 2A-B: People-for-Money}

We next considered prisoner swaps involving monetary exchanges. Participants in Studies 2A-B read that Group B had received a financial demand from Group A (i.e., the ingroup) in order to secure the return one of Group B's prisoners. Here, we manipulated whether Group B accepted Group A's initial monetary offer or negotiated down the price (thereby securing the prisoner on more strategically favorable terms). One advantage of this approach is that it focuses on an outgroup's valuation of its lives independent of the worth of ingroup lives. That is, whereas in our earlier studies, the price paid by the outgroup for its own people is always a specific number of the ingroup's people, here we investigate perceptions of an outgroup's selfworth based on actions it takes to secure its own lives without reference to the value the ingroup places on its own lives.

As in previous studies, we investigated whether Group B's behavior affected perceptions of the group's self-value and perceivers' own respect for the group. Here, we also added in measures of (dis)respectful behavioral intentions towards Group B: support for aggressive and unethical behavior toward Group B. We theorized that, in addition to the extent that perceivers came to disrespect an outgroup based on their beliefs about that outgroup's low self-regard, they might also be less inclined to recommend ethical and civil treatment of the group in subsequent interactions. Indeed, previous work has shown a link between lower perceived regard and worse treatment: for example, in negotiations, the less regard individuals ascribe a counterpart, the more likely they are to engage in aggressive and deceptive tactics, and the less likely they are to 
share information (typically resulting in less 'integrative' outcomes that would generate value; Bear \& Segel-Karpas, 2015; Janoff-Bulman \& Werther, 2008; Kray, Kennedy, \& Van Zant, 2014; Olekalns \& Smith, 2009; SimanTov-Nachlieli, Har-Vardi, \& Moran, 2020). Thus, in Study 2A, we were able to test the links between a group's behavior to perceptions of its self-worth to both respect for that group and willingness to extend it good treatment.

In Study 2B, we then replicated Study 2A using third-party perceivers. Specifically, we wanted to verify whether our results depend on perceivers belonging to one of the groups in conflict. Although it is plausible that perceivers from directly involved outgroups might be particularly affected by any signals they might perceive an outgroup to be sending by their behavior, we reasoned that even third-party perceivers could come to form judgments about how an outgroup values itself based on that group's behavior.

\section{Method}

Study 2A Participants. We preregistered our study on OSF (https://osf.io/kqc45/?view_only=2262f84e1bcb4034a3641344d69c8a5c). Expecting to obtain a small effect based on the results of our other studies, we recruited 554 U.S. residents from Amazon's MTurk. After excluding those who had failed at least one of two attention checks, we were left with a sample of 526 participants $\left(M_{\text {age }}=37.19, S D=12.19 ; 48 \%\right.$ female; 388 Whites/European Americans; 41 Asian/Asian Americans; 25 Latino/Hispanic Americans; 55 Black/African Americans; 3 Middle Eastern/Arab American, 3 Native American, 9 Biracial/Mixed Race). A sensitivity analysis suggested we were adequately powered to detect a small effect of $d=0.25$ at $80 \%$ power.

Study 2B Participants. We preregistered our study on OSF (https://osf.io/s3e9v/?view_only=7dfa73b9ef91469caa937f8755c573ec). We reasoned that we 
might obtain a smaller effect than in previous studies given the third-party nature of this study. We therefore recruited a large sample of 703 U.S. residents from Amazon's MTurk. After excluding those who had failed at least one of two attention checks, we were left with a sample of 683 participants $\left(M_{\text {age }}=37.25, S D=11.88 ; 51 \%\right.$ female; 295 Whites/European Americans; 49 Asian/Asian Americans; 43 Latino/Hispanic Americans; 68 Black/African Americans; 3 MiddleEastern/Arab Americans; 4 Native Americans; 18 Biracial/Mixed Race; 3 Other). A sensitivity analysis suggested we were adequately powered to detect a small effect of $d=0.22$ at $80 \%$ power.

Study 2A-B Design and procedure. Participants were recruited to complete a 10-minute 'Current Events' study in exchange for $\$ 1$. Upon entering the study, participants in this study read that Group B had received a financial demand from Group A in order to secure the return one of Group B's prisoners. Here, we manipulated whether Group B accepted Group A's initial monetary offer or negotiated down the price (thereby securing the prisoner on terms more strategically favorable for the group, but potentially leading perceivers to infer that the group places less value on its citizens' lives). Of note, the information we provided about the focal group's behavior was only in relation to itself (vs. in relation to the conflicting outgroup, as in Studies 1A-B). Specifically, participants were randomly assigned to one of two conditions: an accept initial or a negotiate down condition. Participants in the accept initial condition read that Group A had demanded a price of \$2 million from Group B for the return of one Group B prisoner, and learned that Group B had accepted the offer. In the negotiate down condition, participants read an identical article, except that Group A’s initial demand was \$5 million, with Group B negotiating down the offer to $\$ 2$ million. The text of the manipulation, which was presented in the form of a purportedly real article from a major national newspaper, read as 
follows: "Group A initially offered to return one Group B prisoner in exchange for $\$ 2$ million [\$5 million]. After internal discussions, Group B noted that the payment was a lot of money, but decided to agree to the terms of the prisoner return [and decided to reject the offer and instead start negotiating down the price to be paid]. After several months, the terms of the return were made official [After several rounds of negotiations across several months, an agreement was reached]. According to the terms of the final deal, one Group B prisoner was released in exchange for \$2 million.” (see SOM for full article text). Thus, across both conditions, the final payment was held constant, and only the negotiating strategy employed to reach the final payment was varied. The design and procedure of Study $2 \mathrm{~B}$ was identical, except that participants were simply instructed to read about and evaluate a deal between two groups in conflict, Group A and Group B, without being assigned to either group (i.e., they were thirdparty perceivers). This provides another way of ensuring that the effects of experimental condition are due to the signals sent by Group B's behavior about its self-regard, and not simply intergroup threat (i.e., considerations about the implications of Group B's behavior for Group A). After reading through the article, participants completed our survey before being debriefed and paid. 5

Measures. The items were identical to those in Study 1B, except that we additionally included measures of downstream behavioral intentions (i.e., endorsement of aggressive and unethical bargaining tactics) to move beyond attitudinal measures of respect. Specifically, we

\footnotetext{
${ }^{5}$ We wanted to ensure that the final deal 'valued' the Group B prisoner at the same amount (i.e., $\$ 2$ million) so that any differences in perceived self-regard of Group B could not be accounted for by the final terms of the swap per se (rather than the signal sent by the act of negotiating down versus immediately accepting). Nevertheless, to increase our confidence in this conclusion, we also conducted a version (Supplemental Study 2C) in which the initial offer was held constant at $\$ 2$ million, and Group B either immediately accepted or negotiated the price down (without specifying the final price). Our results were similar (i.e., participants perceived lower self-regard and gave Group B less respect when they negotiated the price down; see SOM).
} 
considered how experimental condition predicted perceptions of Group B's self-regard and how these perceptions related to endorsement of both respectful attitudes and behavioral intentions toward Group B. As with respectful attitudes, we reasoned that perceivers would likely also indicate a willingness to treat groups more disrespectfully (i.e., more aggressively and less ethically) to the extent that they thought they had low self-regard (Stukas \& Snyder, 2016).

Aggressive tactics in future negotiations with Group B. Participants responded to two items regarding their recommendations for how aggressively Group A should negotiate with Group B in the future: whether they would recommend (1) compromising with (reverse-scored) and (2) threatening to use force against Group B (1 = Strongly disagree, 7 = Strongly agree; adapted from Locke, 2014). Though we planned to combine the two items to form our measure of aggressiveness in future negotiations with Group B, their inter-correlation was insufficient to justify scaling them together (i.e., $r(524)=.19, p<.001)$; we therefore considered them separately instead.

Unethical bargaining tactics. Participants completed a shortened 7-item version of the Self-Reported Inappropriate Negotiation Strategies (SINS) scale (Robinson, Lewicki, \& Donahue, 2000), a measure that assesses the appropriateness of engaging in deceptive negotiation strategies (e.g., "Threaten to make Group B look weak or foolish in front of others, even if Group A knows that it won't actually carry out the threat," "Intentionally misrepresent information to Group B in order to strengthen Group A's negotiating arguments or position"; 1 = Not at all appropriate, $7=$ Very appropriate; $\alpha=.92)$.

In Study 2B, we included the same measures (assessed in the same way) as in Study 2A (i.e., perceived self-worth $(\alpha=.60)$, dignity $(\alpha=.84)$, and respect $(\alpha=.97)$. However, we excluded the measures of downstream behavioral intentions because these measures were 
specifically about the use of negotiation tactics when engaged in a conflict with an outgroup (and therefore not applicable to third-party perceivers of a conflict between two groups).

\section{Study 2A-B Results}

Full results for Studies 2A-B are presented in Table 1.

Main effects. In Study 2A, we obtained significant main effects of condition on perceived threat $\left(M_{\text {negotiate }}=3.51, S D=1.39\right.$ vs. $\left.M_{\text {accept }}=3.21, S D=1.35\right), F(1,524)=6.52, p=$ $.011, \eta_{p}^{2}=.01$, but not perceived power, $F(1,524)=2.46, p=.117, \eta_{p}^{2}=.005$. In contrast to Study 2A, in Study 2B, we did not obtain significant main effects of condition on perceived threat, $F(1,681)=0.55, p=.459, \eta_{p}^{2}=.001$, or perceived power, $F(1,681)=0.39, p=.532, \eta_{p}^{2}=$ .001. To follow our pre-registration and to remain consistent with our prior studies, we nevertheless report all results using ANCOVAs that tested the effect of our experimental condition on the key outcome variables while controlling for perceived threat and power; all conclusions are equivalent when these covariates are excluded (see SOM).

In line with — and extending - the results from Study 1B, Study 2A participants in the negotiate down condition perceived that Group B had significantly lower self-worth $(M=4.51$, $S E=.06)$ compared to those in the accept initial condition $(M=4.77, S E=.06)$. They also perceived that Group B had significantly lower dignity $\left(M_{\text {negotiate }}=4.65, S E=.08\right.$ vs. $M_{\text {accept }}=$ $4.87, S E=.08)$. Replicating the results from Study $2 \mathrm{~A}$, participants in the negotiate down condition perceived that Group B had significantly lower self-worth $(M=4.42, S E=.05)$ compared to those in the accept initial condition, $M=4.76, S E=.06)$. Participants in the negotiate down condition also perceived that Group B had significantly lower dignity $(M=4.71$, $S E=.06)$ compared to those in the accept initial condition, $M=4.97, S E=.06)$. 
Moreover, and in line with our predictions, Study 2A participants in the negotiate down condition respected Group B significantly less $(M=4.16, S E=.09)$ than those in the accept initial condition $(M=4.79, S E=.09)$. Replicating the results from Study 2A, Study 2B participants in the negotiate down condition respected Group B significantly less $(M=4.09, S E$ $=.07)$ than those in accept initial condition $(M=4.92, S E=.07)$.

Table 1. Studies $2 A-B$ results controlling for perceived threat and power.

\begin{tabular}{|c|c|c|c|c|c|c|c|c|c|c|c|}
\hline \multirow[b]{3}{*}{ Category } & \multirow[b]{3}{*}{ Construct } & \multicolumn{5}{|c|}{$\begin{array}{c}\text { Study 2A } \\
N=526 ; d f=(1,524)\end{array}$} & \multicolumn{5}{|c|}{$\begin{array}{c}\text { Study 2B } \\
N=683 ; d f=(1,681)\end{array}$} \\
\hline & & \multicolumn{2}{|c|}{$\begin{array}{c}\text { Condition } \\
\text { Adjusted mean (SE) }\end{array}$} & \multicolumn{8}{|c|}{$\begin{array}{c}\text { Condition } \\
\text { Adjusted mean (SE) }\end{array}$} \\
\hline & & $\begin{array}{l}\text { Accept } \\
\text { Initial } \\
\end{array}$ & $\begin{array}{c}\begin{array}{c}\text { Negotiate } \\
\text { Down }\end{array} \\
\end{array}$ & $F$ & $p$ & $\eta_{p}^{2}$ & $\begin{array}{l}\text { Accept } \\
\text { Initial } \\
\end{array}$ & $\begin{array}{c}\text { Negotiate } \\
\text { Down }\end{array}$ & $F$ & $p$ & $\eta_{p}^{2}$ \\
\hline \multirow{3}{*}{$\begin{array}{l}\text { Perceptions } \\
\text { of Self- } \\
\text { Regard }\end{array}$} & $\begin{array}{l}\text { Perceived } \\
\text { self-worth }\end{array}$ & $4.77(.06)$ & $4.51(.06)$ & 8.89 & .003 & .01 & $4.76(.06)$ & $4.42(.05)$ & 19.13 & $<.001$ & .03 \\
\hline & $\begin{array}{l}\text { Perceived } \\
\text { dignity }\end{array}$ & $4.87(.08)$ & $4.65(.08)$ & 4.09 & .04 & .01 & $4.97(.06)$ & $4.71(.06)$ & 8.46 & .004 & .01 \\
\hline & $\begin{array}{l}\text { Perceived } \\
\text { commitment }\end{array}$ & $4.93(.08)$ & $3.88(.08)$ & 82.00 & $<.001$ & .14 & $4.96(.07)$ & $3.89(.07)$ & 108.80 & $<.001$ & .14 \\
\hline \multirow{4}{*}{$\begin{array}{l}\text { Downstream } \\
\text { Outcomes }\end{array}$} & Respect & $4.79(.09)$ & $4.16(.09)$ & 25.93 & $<.001$ & .05 & $4.92(.07)$ & $4.09(.07)$ & 63.91 & $<.001$ & .09 \\
\hline & $\begin{array}{l}\text { Threaten to } \\
\text { use force }\end{array}$ & $2.84(.09)$ & $2.95(.09)$ & 0.66 & .42 & .001 & -- & -- & -- & -- & -- \\
\hline & Compromise & $5.72(.08)$ & $5.84(.08)$ & 1.26 & .26 & .002 & -- & -- & -- & -- & -- \\
\hline & $\begin{array}{l}\text { Unethical } \\
\text { Bargaining } \\
\text { Tactics }\end{array}$ & $3.06(.08)$ & $3.17(.08)$ & 0.91 & .34 & .002 & -- & -- & -- & -- & -- \\
\hline
\end{tabular}

For Study $2 \mathrm{~A}$, in contrast to our predictions, we found no evidence that participants in the negotiate down condition supported more behavior reflecting disrespect towards Group B (i.e., threat to use force against Group B, less willingness to compromise, or use of more unethical bargaining tactics) than participants in the accept initial condition (see Table 1, left column). Given that participants were third-party observers in Study 2B, we did not measure behavioral intentions there.

Indirect effects. As in Studies 1A-B, we examined whether there were indirect effects from condition to respect via self-worth. Given the lack of main effects of condition on the behavioral intentions measures in Study 2A, we ultimately did not consider indirect effects of condition on these variables here (of note, however, we did observe that both perceived self- 
worth and respect were significantly correlated with less negative behavioral intentions, see SOM; we reconsider our proposed indirect effects model in subsequent studies). For all specific indirect effects see Table S5.

Consistent with our predictions, we found in Study 2A that when Group B negotiated down (vs. accepted initial), participants perceived that Group B had lower self-worth which carried significant indirect effects to less respect for Group B (i.e., condition $\rightarrow$ lower self-regard $\rightarrow$ less respect), indirect effect $=-0.192,95 \%$ CI $[-0.314,-0.083]$.

We tested this same model in Study 2B. Replicating Study 2A, we found that when Group B negotiated down the price of the prisoner (vs. accepted the initial price), participants reported less respect for Group B (i.e., condition $\rightarrow$ lower self-worth $\rightarrow$ less respect), indirect effect $=-0.214,95 \%$ CI $[-0.317,-0.122]$.

In sum, across two studies, we extended our results to negotiations involving a monetary exchange, and, in Study 2B, to third-party perceivers. That is, we show that even unaffected perceivers of an intergroup conflict make inferences about the self-worth of another group on the basis of their behavior in a prisoner swap negotiation. Indeed, perceivers come to afford a group less respect when their (strategically beneficial) push for a 'better' deal behavior leads to the perception that that group lacks self-regard. Unexpectedly, however, we did not (in Study 2A, where we examined it) find evidence here that Group B's behavior directly shaped perceivers' behavioral intentions towards the group.

\section{Studies 3A-B: Rejecting the Deal}

In Studies 3A-B, we examined observers' perceptions of an outgroup when it made one of two counter-offers to an uneven prisoner swap proposal, either trying to get more prisoners in return or insisting on an equal trade even though that would mean receiving fewer prisoners or 
releasing more of the other group's prisoners. Consistent with our reasoning thus far (and the findings of Studies 1A-B), we predicted that although pushing for a more lopsided trade could have strategic upsides for the group, it would, by virtue of implicitly accepting a ratio in which the ingroup's lives were worth less than the outgroup's, diminish perceivers' perceptions of the group's self-regard (consistent with Studies 1A-B). In contrast, by insisting on an equal trade (forgoing a lopsided deal in their favor), a group could signal their insistence that their lives are worth no less than the other's. Thus, we expected that a group that insisted on an equal trade would be seen as having higher self-regard and thereby respected more (controlling for any differences across condition in perceptions of the group's threateningness or power). We tested this in the U.S.-Iranian context (Study 3A) and then replicated it in a minimal group context (Study 3B). Of note, we also conducted a third-party minimal groups version of this study, and results are very similar to that of Studies $3 \mathrm{~A}-\mathrm{B}$, so we include the results of this study in SOM (Supplemental Study 3C).

\section{Method}

Study 3A Participants. We preregistered our study on OSF (https://osf.io/q43sn/?view_only=f64bb6fd737a4677ac550d1b53d8efad). We aimed for a sample approximately double that of related pilot studies (see SOM for results of those pilots), and as such, we recruited 852 U.S. residents from Amazon's MTurk. After excluding those who had failed at least one of two attention checks, we were left with a sample of 790 participants $\left(M_{\text {age }}=\right.$ 37.48, $S D=12.20 ; 53 \%$ female; 580 Whites/European Americans; 62 Asian/Asian Americans; 51 Latino/Hispanic Americans; 79 Black/African Americans; 1 Middle Eastern/Arab American; 3 Native American; 12 Biracial/Mixed Race; 2 Other). A sensitivity analysis suggested we were adequately powered to detect a small effect of $d=0.20$ at $80 \%$ power. 
Study 3B participants. We preregistered our study on OSF

(https://osf.io/xsk6n/?view_only=3aa2ecb59a3945cc80de10af6659c204; we made one minor deviation from our pre-registration: since we failed to obtain direct effects of condition on aggressive intentions and unethical behavior, we opted not to conduct indirect effects tests on those outcomes). We recruited 550 U.S. residents from Amazon's MTurk. After excluding those who had failed at least one of two attention checks, we were left with a sample of 383 participants $\left(M_{\text {age }}=37.41, S D=11.61 ; 48 \%\right.$ female; 283 Whites/European Americans; 30 Asian/Asian Americans; 16 Latino/Hispanic Americans; 41 Black/African Americans; 2 Native Americans; 9 Biracial/Mixed Race; 2 Other). A sensitivity analysis suggested we were adequately powered to detect a moderate effect of $d=0.30$ at $80 \%$ power.

Design and procedure. Participants were recruited to complete a 10-minute 'Current Events' study in exchange for $\$ 1$. Upon entering the study, participants were randomly assigned to one of two prisoner swap conditions: an ask for more condition or an ask for equal condition. In Study 3A, in both conditions, participants read that the U.S. had initially offered to return eight Iranian prisoners of war in exchange for one American prisoner. In the ask for more condition, participants then read that Iran had refused this initial deal and instead insisted on receiving 16 Iranian prisoners (i.e., asking for a more unequal deal) in exchange for the one American prisoner. In contrast, in the ask for equal condition, participants then read that Iran had refused this initial deal and instead insisted on either receiving only one Iranian prisoner in exchange for the one American prisoner or on returning eight American prisoners in exchange for the eight Iranian prisoners (i.e., asking for an equal deal). The manipulation was identical in Study 3B except that Group A was substituted for the U.S. and Group B was substituted for Iran. 
After reading the article, participants completed a series of dependent measures and demographics items before being debriefed and paid (see SOM for full manipulation text).

Measures. All measures in this study were identical to that of Studies 2A-B, except that we averaged the two items capturing aggressive tactics because they were robustly correlated in this study $(r=.49, p<.001)$.

\section{Study 3A-B Results}

Full results for Studies 3A-B are presented in Table 2.

Main effects. In Study 3A, we obtained a significant main effect of condition on perceived threat $\left(M_{\text {more }}=4.85, S D=1.23\right.$ vs. $\left.M_{\text {equal }}=3.44, S D=1.63\right), F(1,788)=189.31, p<$ $.001, \eta_{p}^{2}=.19$, but not on perceived power, $F(1,788)=0.33, p=.566, \eta_{p}^{2}=0$. Similar to Study 3A, in Study 3B we obtained a significant main effect of condition on perceived threat $\left(M_{\text {more }}=\right.$ $4.80, S D=1.43$ vs. $\left.M_{\text {equal }}=3.14, S D=1.49\right), F(1,381)=124.02, p<.001, \eta_{p}^{2}=.25$, but not on perceived power, $F(1,381)=0.001, p=.975, \eta_{p}^{2}=0 .^{6}$

Similar to the results from Studies 1A-2B, and as predicted, Study 3A participants in the ask for more condition were significantly less likely to perceive that Iranians, as a people, had high self-worth $(M=4.63, S E=.06)$ compared to those in the ask for equal condition $(M=5.28$, $S E=.06)$. Though in the same direction as the results from Studies 1B-2B, participants in the ask for more condition did not perceive that Iranians had significantly lower dignity $(M=4.08, S E=$ .09) than those in the ask for equal condition, $M=4.26, S E=.09)$. Replicating the results from Study 3A, participants in the ask for more condition perceived that Group B had significantly lower self-worth $(M=3.90, S E=.10)$ compared to those in the ask for equal condition $(M=$

\footnotetext{
${ }^{6} \mathrm{We}$ also included U.S. identification as an additional potential covariate in this study, given the possibility that stronger identification with the U.S. could account for variance in anti-Iran sentiment. Including U.S. identification did not alter results; thus, for the sake of consistency with our other studies, we include results with this covariate only in the SOM.
} 
$5.19, S E=.10)$. Similarly, participants in the ask for more condition perceived that Group B had significantly lower dignity $(M=4.78, S E=.10)$ compared to those in the ask for equal condition $(M=5.22, S E=.10)$.

Replicating the results from Studies 1A-2B, Study 3A participants in the ask for more condition respected Iran significantly less $(M=3.20, S E=.07)$ than those in the ask for equal condition $(M=3.55, S E=.07)$. Replicating the results from Study 3A, Study 3B participants in the ask for more condition respected Group B significantly less $(M=3.82, S E=.11)$ than those in the ask for equal condition $(M=4.57, S E=.12)$.

Finally, we considered the effect of condition on the use of aggressive tactics against Iran and perceptions of the appropriateness of the U.S. engaging in unethical bargaining tactics in future negotiations. In Study 3A, we observed evidence of suppressor variable effects, such that the main effect of condition flipped in sign when we did versus did not control for covariates (i.e., threat and power). Specifically, when controlling for threat and power (as with all analyses reported in the main text), we found, in contrast to predictions, that participants in the ask for more condition were (marginally) less likely to recommend using aggressive tactics against Iran in future negotiations $(M=2.49, S E=.06)$ than participants in the ask for equal condition $(M=$ 2.64, $S E=.06)$. Similarly, participants in the ask for more condition were also significantly less likely to believe that it would be appropriate for the U.S. to engage in unethical bargaining tactics in future negotiations with $\operatorname{Iran}(M=2.90, S E=.06)$ than participants in the ask for equal condition $(M=3.10, S E=.06)$. Highlighting the role of suppression in these results, when we looked at the main effect of condition without any controls, we found (as predicted), that participants in the ask for more condition were actually significantly more likely to endorse aggressive and unethical bargaining tactics (see SOM for further details). Indeed, the unpredicted 
direct effect emerged only after accounting for the (predictable) fact that those in the ask for more condition perceived Iran as more threatening and were therefore more supportive of aggressive and unethical tactics. In contrast to Study 3A, in Study 3B we did not observe main effects of our manipulation on support for the use of aggressive tactics $\left(M_{\text {more }}=2.35, S E=.08\right.$ vs. $\left.M_{\text {equal }}=2.24, S E=.09\right)$ or unethical bargaining tactics $\left(M_{\text {more }}=2.90, S E=.09\right.$ vs. $M_{\text {equal }}=$ 2.96, $S E=.10)$

\begin{tabular}{|c|c|c|c|c|c|c|c|c|c|c|c|}
\hline \multirow[b]{3}{*}{ Category } & \multirow[b]{3}{*}{ Construct } & \multicolumn{5}{|c|}{$\begin{array}{c}\text { Study 3A } \\
N=790 ; d f=(1,788)\end{array}$} & \multicolumn{5}{|c|}{$\begin{array}{c}\text { Study 3B } \\
N=383 ; d f=(1,381)\end{array}$} \\
\hline & & \multicolumn{2}{|c|}{$\begin{array}{c}\text { Condition } \\
\text { Adjusted mean (SE) } \\
\end{array}$} & \multicolumn{8}{|c|}{$\begin{array}{c}\text { Condition } \\
\text { Adjusted mean (SE) }\end{array}$} \\
\hline & & Ask Equal & Ask More & $F$ & $p$ & $\eta_{p}^{2}$ & Ask Equal & Ask More & $F$ & $p$ & $\eta_{p}^{2}$ \\
\hline \multirow{3}{*}{$\begin{array}{l}\text { Perceptions } \\
\text { of Self- } \\
\text { Regard }\end{array}$} & $\begin{array}{l}\text { Perceived } \\
\text { self-worth }\end{array}$ & $5.28(.06)$ & $4.63(.06)$ & 48.53 & $<.001$ & .06 & $5.19(.10)$ & $3.90(.10)$ & 69.89 & $<.001$ & .16 \\
\hline & $\begin{array}{l}\text { Perceived } \\
\text { dignity }\end{array}$ & $4.26(.09)$ & $4.08(.09)$ & 1.78 & .18 & .002 & $5.22(.10)$ & $4.78(.10)$ & 8.76 & .003 & .02 \\
\hline & Perceived & $356(08)$ & $356(08)$ & 0 & 99 & 0 & $425(12)$ & $424(12)$ & .005 & .95 & 0 \\
\hline \multicolumn{12}{|c|}{ Table 2 . Studies $3 A-B$ results controlling for perceived threat and power. } \\
\hline \multirow{3}{*}{$\begin{array}{l}\text { Downstream } \\
\text { Outcomes }\end{array}$} & Respect & $3.55(.07)$ & $3.20(.07)$ & 10.20 & .001 & .01 & $4.57(.12)$ & $3.82(.11)$ & 18.22 & $<.001$ & .05 \\
\hline & $\begin{array}{l}\text { Aggressive } \\
\text { Intentions }\end{array}$ & $2.64(.06)$ & $2.49(.06)$ & 2.82 & .09 & .004 & $2.24(.09)$ & $2.35(.08)$ & 0.77 & .38 & .002 \\
\hline & $\begin{array}{l}\text { Unethical } \\
\text { Bargaining } \\
\text { Tactics }\end{array}$ & $3.10(.06)$ & $2.90(.06)$ & 4.36 & .04 & .006 & $2.96(.10)$ & $2.90(.09)$ & 0.14 & .71 & 0 \\
\hline
\end{tabular}

Indirect effects. We considered how experimental condition predicted perceptions of Iran's self-regard, and how these perceptions related to respect for and endorsement of negative behavioral intentions towards Iran. We considered how perceived self-worth might carry indirect effects from condition to each of attitudinal respect (as in Studies 1A-2B; i.e., condition $\rightarrow$ selfworth $\rightarrow$ respect) and the behavioral intention outcomes (i.e., condition $\rightarrow$ self-worth $\rightarrow$ behavioral intentions). To test these indirect effects, we conducted an indirect effects analysis using observed variables in MPlus v7 (Muthén \& Muthén, 2017) to test our full model, with attitudinal respect, and intentions to behave (dis)respectfully (i.e., aggressiveness in future 
negotiations, and unethical bargaining tactics) as the outcome measures. For all specific indirect effects in each of the models, see Table S10.

We begin with the results for Study 3A. First examining respect for Iran, we found evidence for our hypothesized significant indirect effect through perceived self-worth. Replicating Studies 1A-2B, and consistent with our predictions, we found that when Iranians were thought to ask for more (vs. ask for equal), American participants afforded less respect towards Iran through a decrease in perceptions of Iranians' self-worth (i.e., condition $\rightarrow$ lower self-worth $\rightarrow$ less respect), indirect effect $=-0.238,95 \%$ CI $[-0.328,-0.155]$.

Next, examining endorsement of the use of aggressive tactics towards Iran, we found evidence for our hypothesized significant indirect effect through perceived self-worth. Consistent with our predictions, we found that when Iranians were thought to ask for more (vs. ask for equal), American participants responded with higher aggressiveness towards Iran through a decrease in perceptions of Iranians' self-worth (i.e., condition $\rightarrow$ lower self-worth $\rightarrow$ greater aggressiveness), indirect effect $=0.149,95 \%$ CI $[0.078,0.223]$.

Finally, when considering unethical bargaining tactics, we again observed a significant indirect effect from condition via self-worth (i.e., condition $\rightarrow$ lower self-worth $\rightarrow$ more unethical tactics), indirect effect $=0.082,95 \%$ CI $[0.022,0.147]$.

In Study 3B we only tested (using PROCESS) whether experimental condition affected respect via perceptions of Group B's self-regard (we did not test indirect effects to aggressiveness or unethical bargaining tactics, since we observed no main effects of condition on either of these outcomes). Consistent with our predictions and replicating previous studies, we found evidence for a significant indirect effect of condition through self-worth: when Group B asked for more prisoners (vs. asked for equal), participants reported less respect for Group B via 
decreased perceptions of Group B self-worth (i.e., condition $\rightarrow$ lower self-worth $\rightarrow$ less respect; indirect effect $=-0.698,95 \%$ CI $[-0.913,-0.509])$.

Across Studies 3A-B, we found that groups can overcome the tendency to be seen as lower in self-regard by instead insisting on equal trades (rather than more unequal ones). In essence, we further confirmed the role of lopsidedness in reducing self-regard because we find that making a costly commitment to equality improves perceptions of self-regard.

\section{Study 4: Leave No Person Behind}

Given the importance of prisoner swaps as a pathway towards reconciliation, Studies 1A3B focused specifically on that context, highlighting how pushing to get a 'better deal' can ironically diminish perceptions of a group's self-regard and the respect it is afforded. Although better understanding the contours by which respect is afforded or withheld in the context of prisoner swaps is undoubtedly important in its own right, our reasoning reflects the more general theoretical proposition that, as with interpersonal relations (Gurung \& Chrouser, 2007; Holland \& Haslam, 2013; McElroy et al., 2014; Swami \& Furnham, 2007), groups’ behavior can (sometimes ironically) shape perceptions of their self-worth, with consequences for how they are seen and treated. In our final study, we moved beyond the prisoner swap context to provide initial evidence for the generality of this framework. In particular, we consider perceptions of a group that chose to either engage or decline to engage in a mission to save a group member that placed the lives of other group members in direct risk. This scenario enables us to examine another situation with real-world relevance: the concept of 'leaving no one behind' is often espoused by armies (including, for example, the U.S. and Israel; Cortellessa, 2015; Daileda, 2014). Here, we experimentally examine whether this philosophy actually confers perceptions of high self-worth (and ultimately, respect). Participants were told about a fallen ingroup soldier 
that was certain to die unless members of the group were able to rescue him. Participants learned that choosing to take on the rescue mission had a $40 \%$ probability of killing five ingroup rescue soldiers. Because an expected value calculation suggests that engaging in the mission would result in a net loss of ingroup life $(0.40 * 5=2$ ingroup lives lost in pursuit of saving a single ingroup life), the strategically beneficial course of action in terms of preserving ingroup lives would be to decline to engage in the mission. We reasoned, however, that groups that declined to engage in the risky rescue effort might be seen as having lower self-regard (with implications for respect), even though, ironically, this decision would (on average) save ingroup lives.

\section{Method}

Participants. We conducted two identical preregistered studies (Version 1: https://osf.io/3fr48/?view_only=592dd0ddac814e0dbcfa883f3cbafe58; Version 2: https://osf.io/5tcmg/?view_only=4c360c011acb4043bd793f44af4c9659). Here, we present them combined as a single study, since the two studies were identical in nature, and results were largely equivalent when analyzing the two studies separately (we provide results of the two studies separately in SOM). Expecting to obtain a small effect similar to previous studies, we recruited two large samples of U.S. residents from Amazon's MTurk $\left(N_{l}=649 ; N_{2}=700\right)$. After excluding those who had failed at least one of two attention checks, we were left with a sample of 1052 participants across both studies $\left(M_{\text {age }}=37.41, S D=11.82 ; 54 \%\right.$ female; 793 Whites/European Americans; 75 Asian/Asian Americans; 67 Latino/Hispanic Americans; 80 Black/African Americans; 1 Middle Eastern/Arab American; 5 Native American; 29 Biracial/Mixed Race; 2 Other). A sensitivity analysis suggested we were adequately powered to detect a small effect of $d=0.17$ at $80 \%$ power. 
Design and procedure. Participants were recruited to complete a 10-minute 'Current Events' study in exchange for \$1. Upon entering the study, participants were randomly assigned to one of two conditions: an engage action or a reject action condition. In both conditions, participants read that a Group B prisoner had been taken hostage by Group A, and that Group B's military was considering whether to engage in a rescue mission. In both conditions, an analysis indicated that the potential risk of the operation was a $40 \%$ chance of 5 Group B soldiers being killed (i.e., expected value $=2$ soldiers killed, in a rescue mission with a maximum potential of saving a solitary soldier). Participants in the engage action condition then read that Group B chose to engage in the rescue mission. Participants in the reject action condition read an identical scenario, except that Group B chose not to engage in the rescue mission. The text of the manipulation, which was presented in the form of a hypothetical scenario, read as follows: "The Generals of Group B's army carefully assessed the plan. After conferring, they decided to [not to] pursue the operation." (see SOM for full scenario text). Thus, across both conditions, the risk of the mission was held constant, and we varied only whether Group B engaged in the mission.

Measures. The measures included were the same as in Study 3B, except that we did not include negative behavioral intentions measures. That is, we included perceived self-worth, dignity, and respect. Although the exact items for each of these scales were very similar to those in Study 3B, we made a few modifications (see SOM for full scales). In prior studies using thirdparty perceivers, we had excluded the negative behavioral intentions items because the items focused on behavior towards a group with whom one was in conflict (which was not relevant to the third-party perceiver case). Here, we decided to develop relevant behavioral intention items that could apply to the third-party perceiver case, involving potential positive acts that the thirdparty perceiver might engage in to aid the focal group. 
Positive behavioral intentions. Participants responded to a series of three items designed to assess participants' desire for the U.S. to engage in actions to support Group B and help mediate the conflict between Group A and Group B. We chose to focus on potential provision of support and mediation of conflict, given that the U.S. was a third party in this case, making unethical and aggressive tactics less relevant in this context. Furthermore, following research on individual self-esteem (e.g., Schlenker \& Leary, 1982), we reasoned that, if Group B was perceived to have high self-regard, third-party perceivers would be more likely to recommend engaging in positive actions to support Group B than if they were perceived to have lower selfregard. The three items were: "Do you think that the U.S. should extend an invitation to host the leaders of Group B at the White House?", "Do you think that the U.S. should offer medical and/or humanitarian aid to Group B?", and "Do you think that the U.S. should offer to mediate the dispute between Group A and Group B?” $(\alpha=.71)$.

\section{Results}

Full results for Study 4 are presented in Table 3.

We obtained a significant main effect of condition on perceived threat $\left(M_{\text {reject }}=3.47, S D\right.$ $=1.11$ vs. $\left.M_{\text {engage }}=4.05, S D=1.20\right), F(1,1050)=35.12, p<.001, \eta_{p}^{2}=.06$, and on perceived power $\left(M_{\text {reject }}=3.38, S D=1.05\right.$ vs. $\left.M_{\text {engage }}=3.86, S D=1.02\right), F(1,1050)=29.76, p<.001, \eta_{p}^{2}$ $=.05$. We report all results using ANCOVAs that tested the effect of our experimental condition on the key outcome variables while controlling for perceived threat and power; all conclusions are equivalent when these covariates are excluded.

As predicted, participants in the reject action condition perceived Group B to have significantly lower self-worth $(M=5.27, S E=.04)$ compared to those in the engage action condition $(M=5.63, S E=.04)$. Participants in the reject action condition also perceived that 
Group B had significantly lower dignity $(M=4.91, S E=.05)$ compared to those in the engage action condition, $(M=5.69, S E=.05)$.

As predicted, participants in the reject action condition respected Group B significantly less $(M=4.87, S E=.06)$ than those in the engage action condition $(M=5.51, S E=.06)$. Finally, participants in the reject action condition were significantly less likely to recommend that the U.S. help Group B $(M=4.39, S E=.06)$ than those in the engage action condition $(M=4.66, S E$ $=.06)$.

Table 3. Study 4 results controlling for perceived threat and power.

\begin{tabular}{cllcccc}
\hline & \multicolumn{5}{c}{$N=1052 ; d f=(1,1050)$} & \\
\hline & & \multicolumn{2}{c}{$\begin{array}{c}\text { Condition } \\
\text { Adjusted mean (SE) }\end{array}$} \\
\cline { 2 - 7 } & $\begin{array}{c}\text { Engage } \\
\text { Action }\end{array}$ & $\begin{array}{c}\text { Reject } \\
\text { Action }\end{array}$ & $F$ & $p$ & $\eta_{p}^{2}$ \\
\hline & $\begin{array}{l}\text { Perceived self- } \\
\text { worth }\end{array}$ & $5.63(.04)$ & $5.27(.04)$ & 31.64 & $<.001$ & .03 \\
$\begin{array}{c}\text { Perceptions } \\
\text { of Self- } \\
\text { Regard }\end{array}$ & $\begin{array}{l}\text { Perceived } \\
\text { dignity }\end{array}$ & $5.69(.05)$ & $4.91(.05)$ & 128.48 & $<.001$ & .11 \\
& $\begin{array}{l}\text { Perceived } \\
\text { commitment }\end{array}$ & $5.38(.06)$ & $4.83(.06)$ & 43.99 & $<.001$ & .04 \\
\hline \multirow{2}{*}{$\begin{array}{c}\text { Downstream } \\
\text { Outcomes }\end{array}$} & $\begin{array}{l}\text { Respect } \\
\text { Positive }\end{array}$ & $5.51(.06)$ & $4.87(.06)$ & 57.34 & $<.001$ & .05 \\
& $\begin{array}{l}\text { Behavioral } \\
\text { Intentions }\end{array}$ & $4.66(.06)$ & $4.39(.06)$ & 11.04 & .001 & .01 \\
\hline
\end{tabular}

Indirect effects. We conducted a mediation analysis using observed variables in MPlus to test our full indirect effects model, with respect and positive behavioral intentions as the outcome measures. For all specific indirect effects, see Table S17.

First, we found evidence for significant indirect effects of condition on respect through self-worth, consistent with our predictions and replicating previous studies: When Group B declined to pursue the risky rescue mission (versus choosing to engage in it, despite the net loss of lives in terms of expected value), participants perceived that Group B had significantly lower 
self-worth, which predicted less respect for Group B (i.e., condition $\rightarrow$ lower self-worth $\rightarrow$ less respect), indirect effect $=-0.262,95 \% \mathrm{CI}[-0.354,-0.169]$.

Consistent with our predictions, we also found evidence for significant indirect effects of experimental condition on respectful behavioral intentions through self-worth. Specifically, we found that when Group B rejected action (vs. engaged action), participants perceived that Group B had significantly lower self-worth, which ultimately predicted a lower likelihood of recommending that the U.S. engage in supportive actions toward Group B (i.e., condition $\rightarrow$ lower self-worth $\rightarrow$ lower likelihood of recommending positive behaviors toward Group B), indirect effect $=-0.124,95 \%$ CI $[-0.176,-0.076]$.

In sum, Study 4 highlighted that our theorizing about the link between group behaviors and perceptions of a group's self-regard extends outside the direct context of prisoner swaps. Our results showed how another group behavior in conflict—-here, the strategically beneficial decision to 'leave a man behind' in order to save two - can diminish perceptions of a group's self-regard, with consequences for the respect and respectful behavioral (intentions) that group is afforded.

\section{Internal Meta-Analysis}

Given the similar hypothesizing and measures available across the studies presented here, we meta-analyzed the central findings utilizing a fixed-effects approach across the seven studies to determine the robustness of the observed effects (results are highly similar when utilizing a random-effects approach, which we report in the SOM; Goh, Hall, \& Rosenthal, 2016). In particular, across studies, we contrasted all conditions in which a group took a strategically beneficial action that could be interpreted as implying lower self-worth to conditions that were less strategically beneficial but affirmed self-worth. Our key results on lower self-regard and 
diminished respect were robust when meta-analyzed across the seven studies - both with and without covariates. Specifically, participants in the strategically beneficial (vs. less strategically beneficial) action condition reliably (a) perceived the group to have lower self-worth, (b) less dignity, and (c) less commitment to the group. They also indicated (d) less respect for the group. The results on aggressive and unethical bargaining tactics (which were based on fewer studies) were more tentative: effects were significant when covariates were not included, but not robust when we controlled for threat and power. Note however that indirect effects (i.e., from condition $\rightarrow$ self-regard $\rightarrow$ aggression/unethicality) were significant whenever tested. For full results of our internal meta-analysis, see Table 4 (additional meta-analytic results are provided in SOM).

Table 4. Internal meta-analysis results.

\begin{tabular}{|c|c|c|c|c|c|c|c|c|c|}
\hline & & \multicolumn{4}{|c|}{ With Covariates } & \multicolumn{4}{|c|}{ Without Covariates } \\
\hline & & Studies & Stouffer $Z$ & $p$ & Meta $r$ & Studies & Stouffer $Z$ & $p$ & Meta $r$ \\
\hline \multirow{3}{*}{$\begin{array}{c}\text { Perceptions } \\
\text { of Self- } \\
\text { Regard }\end{array}$} & $\begin{array}{l}\text { Perceived } \\
\text { self-worth }\end{array}$ & 6 & 15.08 & $<.001$ & .24 & 7 & 15.43 & $<.001$ & .30 \\
\hline & $\begin{array}{l}\text { Perceived } \\
\text { dignity }\end{array}$ & 6 & 10.74 & $<.001$ & .24 & 6 & 13.93 & $<.001$ & .25 \\
\hline & $\begin{array}{l}\text { Perceived } \\
\text { commitment }\end{array}$ & 6 & 11.23 & $<.001$ & .19 & 7 & 9.43 & $<.001$ & .20 \\
\hline \multirow{4}{*}{$\begin{array}{l}\text { Respectful } \\
\text { Attitudes } \\
\text { and } \\
\text { Intentions }\end{array}$} & Respect & 6 & 13.22 & $<.001$ & .22 & 7 & 15.64 & $<.001$ & .30 \\
\hline & Aggressiveness & 2 & 1.87 & .061 & .05 & 2 & 6.46 & $<.001$ & .18 \\
\hline & $\begin{array}{l}\text { Unethical } \\
\text { Bargaining } \\
\text { Tactics }\end{array}$ & 3 & 1.37 & .171 & .03 & 3 & 4.86 & $<.001$ & .12 \\
\hline & $\begin{array}{l}\text { Prosocial } \\
\text { Intentions }\end{array}$ & 1 & 3.24 & .001 & .10 & 1 & 5.51 & $<.001$ & .17 \\
\hline \multirow{3}{*}{ Covariates } & Threat & -- & -- & -- & -- & 6 & 12.68 & $<.001$ & .25 \\
\hline & & & & & & & & & \\
\hline & Power & -- & -- & -- & -- & 6 & 4.79 & $<.001$ & .09 \\
\hline
\end{tabular}

Note. For meta-analysis of results with covariates included, we are limited to six studies where we measured covariates: Studies 1B, 2A-B, 3A-B, and 4. For meta-analysis of results without covariates, we include all Studies $1 \mathrm{~A}-4$.

\section{General Discussion}

Prisoner swaps have historically played an important role in reconciliation, often serving as an initial opening towards the resolution of active conflict (Baskin, 2020; Korte, 2016;

Kramer, 2019; Pillar, 2014). Here, we consider how certain group actions in prisoner swaps can 
ironically shape how they are seen, and, importantly, the respect (and, in certain cases, treatment) they are afforded as a result. In particular, groups who agreed to (vs. rejected) favorable lopsided prisoner swaps were respected less — despite engaging in strategically beneficial behaviorbecause perceivers interpreted their actions as signaling lower self-regard. We observed these effects using both real-world and minimal groups, and among parties to the intergroup conflict and third-party perceivers. Moreover, our results held even when accounting for perceptions of group threat and power. In a final study, we provided initial evidence that these effects hold beyond just the context of prisoner swaps: groups who avoided (vs. pursued) a rescue mission expected to kill more ingroup soldiers than it saved were also seen as having lower self-regard, with similar consequences for others' respect and treatment of the group. To our knowledge, our work is the first to examine how perceivers might come to make attributions about the worthiness of groups as a function of how these groups are thought to see themselves.

Our work has important practical implications. Typically, uneven trades occur between groups in asymmetric power relationships (e.g., a 1,027:1 trade between Israel and Palestine; Wilkinson, 2011), and are celebrated by the low-power side securing more of their people. Our work sounds a note of caution: by implicitly accepting a ratio that 'prices' outgroup lives as more valuable than their own, the low-power side risks observers - even passive, third-party observers - coming to infer that their group has low self-regard, further compounding an existing tendency to see groups lower in power and/or status to be seen as less worthy (e.g., Harris \& Fiske, 2018; Petsko, Lei, Kunst, Bruneau, \& Kteily, in press; Lammers \& Stapel, 2011). At the same time, one implication of our work is that forgoing certain strategically advantageous outcomes in order to affirm their self-regard (e.g., insisting on a 1:1 instead of a 1:many trade, as in Studies 3A-3B) may be one way disempowered groups can powerfully signal that they see 
their lives as no less valuable than anyone else's, potentially increasing others' valuation of their worthiness (and respect for them). Of course, disempowered groups would presumably prefer to simultaneously capitalize on strategically advantageous outcomes while circumventing the associated "hit" to perceptions of their self-regard. It would be interesting for future research to consider how groups might best accomplish this. For example, groups might explicitly accentuate the strategic value of the outgroup person they returned, thereby mitigating any attribution that ingroup lives are generally less valuable than outgroup lives even if the numerical ratio of people exchanged in a particular swap is lopsided (see also footnote 1). Alternatively, groups might consider directly addressing the lopsidedness after a deal is struck, taking pains to dispel the notion that the deal reflects on their self-regard.

Theoretically, our work begins to illuminate how attribution processes identified by research at the interpersonal level may extend to the intergroup domain. Just as individuals' behavior can sometimes be interpreted as reflecting on their self-regard even when this isn't consistent with how individuals see themselves (Moffitt \& Szymanski, 2011), we document that groups' actions can send subtle signals about how highly they value themselves, shaping perceivers' judgments of their group worth. Our work showed that this pathway from group behavior to judgments of that group via perceptions of its self-regard generalized beyond the prisoner swap context. Moreover, whereas our work focused on ironic judgments of low selfregard in response to groups engaging in strategically beneficial behavior, we expect that this process reflects a more general mechanism by which individuals come to judge groups (including in cases where strategically beneficial behavior leads to judgments of high self-worth and strategically costly behavior does the reverse). Notably, we also show that perceptions of a group's low self-regard can co-exist with perceptions that that group poses a threat. In several 
studies, we found that pushing for more in a prisoner swap resulted in a group being seen as posing more of a threat even as it also made the group seem like it placed a low value on itself. Future work could consider when and why these perceptions co-occur (even as they exert independent effects on respect and behavioral intentions). For example, it might be that perceptions of a terrorist group's lower regard for the value of their own group's lives is associated with perceiving them as posing a dangerous threat (to the extent that they are thought to be willing to sacrifice ingroup lives to hurt others).

\section{Limitations \& Future Directions}

Despite our work's contributions, we note several limitations and outstanding questions. First, despite robust effects of the terms of prisoner swaps on respect for the target group via perceived self-regard, the link between prisoner swap terms and intentions to engage in (dis)respectful behavior was less robust, overall, to the inclusion of covariates (threat and power). It may be that perceived self-regard has weaker effects on the antisocial behavioral intentions we considered in Studies 2A, 3A, and 3B-disrespecting a group seen to have low self-regard might lead more to avoidance than active aggression toward them. Indeed, in Study 4, we focused on positive behavioral intentions and found clear evidence that perceivers wanted to help groups more the more they thought that group had high self-regard. Future research should further investigate the conditions under which perceived self-regard predicts behavior, including potentially by directly manipulating whether a group is said to hold itself in high versus lowesteem.

Second, the current studies focused exclusively on online samples of U.S. participants. It therefore remains to be seen whether our results would hold among participants who are not members of a high-power group. Moreover, our samples were online only, and some of our 
measures were created specifically for the studies presented here. Future research should examine these effects in other diverse participant samples, including non-U.S. participants, and participants in the field or in the lab, utilizing other measures that could be proxies of self-worth.

Future work should consider other contexts in which groups send signals about their selfworth. We focused here primarily on the consequential context of prisoner swaps. Still, other relevant contexts abound, ranging from individual everyday encounters between two citizens of groups previously involved in a prisoner swap to citizens' willingness to accept or protest corrupt governance. Indeed, countries' internal behavior might serve as a signal of worth. For example, the political leadership in Lebanon recently disregarded public safety by failing to safely dispose of a store of toxic chemicals that caused the recent and devastating explosion at the port in Beirut (resulting in 190 fatalities and many injuries), despite having known about it for six years (Abouzeid, Habib, Jabbour, Mokdad, \& Nuwayhid, 2020). Onlookers might infer from this governmental negligence that the Lebanese place low (self-)worth on their lives; the Lebanese public's vocal outrage, citizen-led efforts to rebuild, and protests calling for their government's resignation could serve to correct any such impressions. Relatedly, it is worth considering the relationship between our findings and the findings of research on low status group members' resistance to dependency-oriented help from their high-status counterpart (e.g., Halabi, Dovidio, \& Nadler, 2016; Nadler, 2002), both of which highlight the potential for a seemingly-beneficial exchange to reinforce existing disparities.

\section{Conclusion}

We demonstrate a novel and important determinant of perceivers' attributions about the worthiness of other groups: the signals that group's actions in prisoner swaps may send about its own self-regard. Our work suggests that pursuing actions with strategically-beneficial outcomes 
can ironically lead to groups being seen as lacking self-regard, disrespected, and sometimes even mistreated. Our work suggests that, in pursuing certain courses of action, groups who negotiate a 'better' deal may actually come to be seen as worth less.

\section{Open Practices}

The experiments in this article utilized the following open scientific practices: all studies were preregistered, have open materials, and open data. We provide the materials, raw data sets, and syntax for analyses on the Open Science Framework at the following link: https://osf.io/tafeg/?view_only=288036073dde459d841adbf0b8f5dce9. Links to each study preregistration are included within the Methods section of each study. 


\section{References}

Abouzeid, M., Habib, R. R., Jabbour, S., Mokdad, A. H., \& Nuwayhid, I. (2020). Lebanon's humanitarian crisis escalates after the Beirut blast. The Lancet.

Al-Haj, A. (2019, January 31). Yemeni officials: Saudis release 7 Yemeni rebel prisoners. Retrieved from https://apnews.com/a9c88503236246abb3b655e3d439cc05

Allison, M. (2012, August 15). Peace in Northern Ireland: A model of success? Retrieved from https://www.aljazeera.com/indepth/opinion/2012/08/201281292223454712.html

al-Mughrabi, N. \& Heller, J. (2011, October 17). Israeli soldier Shalit, Palestinians freed in captive swap. Retrieved from https:/www.reuters.com/article/us-palestinians-israelprisoners/israeli-soldier-shalit-palestinians-freed-in-captive-swapidUSTRE79E2YG20111018

Anderson, C., Brion, S., Moore, D. A., \& Kennedy, J. A. (2012). A status-enhancement account of overconfidence. Journal of Personality and Social Psychology, 103(4), 718-735.

Andrighetto, L., Riva, P., Gabbiadini, A., \& Volpato, C. (2016). Excluded from all humanity: Animal metaphors exacerbate the consequences of social exclusion. Journal of Language and Social Psychology, 35(6), 628-644.

Baker, P. (2016, January 18). U.S.-Iranian swaps pit compassion against costs. Retrieved from https://www.nytimes.com/2016/01/19/us/politics/us-iranian-swaps-pit-compassion-againstcosts.html?_r=0

Baskin, M. (2020, March 17). Negotiation analysis: The US, Taliban, and the Bergdahl exchange. Retrieved from https://www.pon.harvard.edu/daily/international-negotiationdaily/negotiation-analysis-the-us-taliban-and-the-bergdahl-exchange/

Bear, J. B., \& Segel-Karpas, D. (2015). Effects of attachment anxiety and avoidance on negotiation propensity and performance. Negotiation and Conflict Management Research, 8(3), 153-173.

Belfast Telegraph (2012, May 14). Tolerance and respect key to our shared future. Retrieved from https://www.belfasttelegraph.co.uk/opinion/news-analysis/tolerance-and-respect-keyto-our-shared-future-28748814.html

Bruneau, E., \& Kteily, N. (2017). The enemy as animal: Symmetric dehumanization during asymmetric warfare. PloS one, 12(7), e0181422. 
Cortellessa, E. (2015, September 8). For the IDF, leaving no one behind is more than a mission. Retrieved from https://www.timesofisrael.com/for-the-idf-leaving-no-one-behind-is-morethan-a-mission/\#gs.fm916d

Daileda, C. (2014, June 14). The military history of 'leave no man behind.' Retrieved from https://mashable.com/2014/06/14/bowe-bergdahl-are-american-military-soldiers-ever-leftbehind/

Darwall, S. L. (1977). Two kinds of respect. Ethics, 88(1), 36-49.

Drinen, D. (2008). Approximate value. Retrieved from https://www.pro-footballreference.com/blog/index $37 \mathrm{a} 8 . \mathrm{html}$

Epley, N., Keysar, B., Van Boven, L., \& Gilovich, T. (2004). Perspective taking as egocentric anchoring and adjustment. Journal of Personality and Social Psychology, 87(3), 327-339.

Fiedler, K., Harris, C., \& Schott, M. (2018). Unwarranted inferences from statistical mediation tests-An analysis of articles published in 2015. Journal of Experimental Social Psychology, 75, 95-102.

Fiske, S. T., \& Dépret, E. (1996). Control, interdependence and power: Understanding social cognition in its social context. European Review of Social Psychology, 7(1), 31-61.

Friedrichs, J. (2016). An intercultural theory of international relations: how self-worth underlies politics among nations. International Theory, 8(1), 63-96.

Gaertner, S. L., Dovidio, J. F., Banker, B. S., Houlette, M., Johnson, K. M., \& McGlynn, E. A. (2000). Reducing intergroup conflict: From superordinate goals to decategorization, recategorization, and mutual differentiation. Group Dynamics: Theory, Research, and Practice, 4(1), 98.

Galeotti, A. E. (2010). Respect as recognition: Some political implications. In The plural states of recognition (pp. 78-97). Palgrave Macmillan, London.

Goh, J. X., Hall, J. A., \& Rosenthal, R. (2016). Mini meta-analysis of your own studies: Some arguments on why and a primer on how. Social and Personality Psychology Compass, 10(10), 535-549.

Golec de Zavala, A. G., Cichocka, A., Eidelson, R., \& Jayawickreme, N. (2009). Collective narcissism and its social consequences. Journal of Personality and Social Psychology, 97(6), 1074-1096. 
Gurung, R. A., \& Chrouser, C. J. (2007). Predicting objectification: Do provocative clothing and observer characteristics matter? Sex Roles, 57(1-2), 91-99.

Halabi, S., Dovidio, J. F., \& Nadler, A. (2016). Help that hurts? Perceptions of intergroup assistance. International Journal of Intercultural Relations, 53, 65-71.

Harris, L. T., \& Fiske, S. T. (2018). Dehumanizing the lowest of the low: Neuroimaging responses to extreme out-groups. In Social Cognition (pp. 215-226). Routledge.

Haslam, N. (2006). Dehumanization: An integrative review. Personality and Social Psychology Review, 10(3), 252-264.

Hayes, A. F. (2017). Introduction to mediation, moderation, and conditional process analysis: A regression-based approach. Guilford Publications.

Holland, E., \& Haslam, N. (2013). Worth the weight: The objectification of overweight versus thin targets. Psychology of Women Quarterly, 37(4), 462-468.

Janoff-Bulman, R., \& Werther, A. (2008). The social psychology of respect: Implications for delegitimization and reconciliation. The Social Psychology of Intergroup Reconciliation, 145-170.

Korte, G. (2016, January 17). Obama: Iran deal makes the world safe. Retrieved from https://www.usatoday.com/story/news/politics/2016/01/17/obama-iran-deal-makes-world$\underline{\text { safer/78931152/ }}$

Kramer, A. (2019, December 29). With prisoner swap, Ukraine's president inches toward peace with separatists. Retrieved from https://www.nytimes.com/2019/12/29/world/europe/ukraine-russia-prisoner-swap.html

Kray, L. J., Kennedy, J. A., \& Van Zant, A. B. (2014). Not competent enough to know the difference? Gender stereotypes about women's ease of being misled predict negotiator deception. Organizational Behavior and Human Decision Processes, 125(2), 61-72.

Kteily, N., Bruneau, E., Waytz, A., \& Cotterill, S. (2015). The ascent of man: Theoretical and empirical evidence for blatant dehumanization. Journal of Personality and Social Psychology, 109(5), 901-931.

Kteily, N., Hodson, G., \& Bruneau, E. (2016). They see us as less than human: Metadehumanization predicts intergroup conflict via reciprocal dehumanization. Journal of Personality and Social Psychology, 110(3), 343-370. 
Kteily, N., Saguy, T., Sidanius, J., \& Taylor, D. M. (2013). Negotiating power: Agenda ordering and the willingness to negotiate in asymmetric intergroup conflicts. Journal of Personality and Social Psychology, 105(6), 978-995.

Lammers, J., \& Stapel, D. A. (2011). Power increases dehumanization. Group Processes \& Intergroup Relations, 14(1), 113-126.

Larson, D. W. (1988). The psychology of reciprocity in international relations. Negotiation Journal, 4(3), 281-301.

Leidner, B., Castano, E., \& Ginges, J. (2013). Dehumanization, retributive and restorative justice, and aggressive versus diplomatic intergroup conflict resolution strategies. Personality and Social Psychology Bulletin, 39(2), 181-192.

Lennon, S. J., Johnson, K. K., \& Schulz, T. L. (1999). Forging linkages between dress and law in the US, part I: Rape and sexual harassment. Clothing and Textiles Research Journal, 17(3), 144-156.

Locke, K. D. (2014). Circumplex scales of intergroup goals: An interpersonal circle model of goals for interactions between groups. Personality and Social Psychology Bulletin, 40(4), 433-449.

Muthén, L. K., \& Muthén, B. (2019). Mplus: The comprehensive modelling program for applied researchers: User's Guide, Vol. 5.

Macrae, C. N., \& Quadflieg, S. (2010). Perceiving people. In S. T. Fiske, D. T. Gilbert, \& G. Lindzey (Eds.), Handbook of Social Psychology (pp. 428-463). Hoboken, NJ, US: John Wiley \& Sons Inc.

Madon, S., Willard, J., Guyll, M., \& Scherr, K. C. (2011). Self-fulfilling prophecies: Mechanisms, power, and links to social problems. Social and Personality Psychology Compass, 5(8), 578-590.

McElroy, J. C., Summers, J. K., \& Moore, K. (2014). The effect of facial piercing on perceptions of job applicants. Organizational Behavior and Human Decision Processes, 125(1), 26-38.

Moffitt, L. B., \& Szymanski, D. M. (2011). Experiencing sexually objectifying environments: A qualitative study. The Counseling Psychologist, 39(1), 67-106.

Morris, S. (2014). Lessons from New Zealand: Towards a better working relationship between indigenous peoples and the state. Australian Indigenous Law Review, 18(2), 67-87. 
Nadler, A. (2002). Inter-group helping relations as power relations: Maintaining or challenging social dominance between groups through helping. Journal of Social Issues, 58(3), 487-502.

Northern Ireland Executive (2020, February 27). Statistical bulletin: Indicator 26 a respect index for Northern Ireland (as measured by the Everyday Discrimination Scale). Retrieved from https://www.northernireland.gov.uk/node/42786

Olekalns, M., \& Smith, P. L. (2009). Mutually dependent: Power, trust, affect and the use of deception in negotiation. Journal of Business Ethics, 85(3), 347-365.

Opotow, S. (1990). Moral exclusion and injustice: An introduction. Journal of Social Issues, 46(1), 1-20.

Orehek, E., \& Weaverling, C. G. (2017). On the nature of objectification: Implications of considering people as means to goals. Perspectives on Psychological Science, 12(5), 719730.

Petsko, C. D., Lei, R., Kunst, J. R., Bruneau, E., \& Kteily, N. (in press). Blatant dehumanization in the mind's eye: Prevalent even among those who explicitly reject it? Journal of Experimental Psychology: General.

Pillar, P. (2014). Negotiating peace: War termination as a bargaining process. Princeton University Press.

Pratto, F., \& Glasford, D. E. (2008). Ethnocentrism and the value of a human life. Journal of Personality and Social Psychology, 95(6), 1411-1428. http://doi.org/10.1037/a0012636

Pratto, F., Glasford, D. E., \& Hegarty, P. (2006). Weighing the prospects of war. Group Processes \& Intergroup Relations, 9(2), 219-233.

Ramsbotham, O., Miall, H., \& Woodhouse, T. (2011). Contemporary conflict resolution. Polity. Reuters (2020, June 8). Iranian-American freed in prisoner swap with U.S. arrives in Iran. Retrieved from https://www.reuters.com/article/us-iran-usa-prisoners/iranian-americanfreed-in-prisoner-swap-with-u-s-arrives-in-iran-idUSKBN23F0UN

Robinson, R. J., Lewicki, R. J., \& Donahue, E. M. (2000). Extending and testing a five factor model of ethical and unethical bargaining tactics: Introducing the SINS scale. Journal of Organizational Behavior, 649-664.

Rotman, Y. (2009). Byzantine slavery and the Mediterranean world, (pp. 27-56). Harvard University Press. 
Sachdev, I., \& Bourhis, R. Y. (1987). Status differentials and intergroup behaviour. European Journal of Social Psychology, 17(3), 277-293.

Schlenker, B. R., \& Leary, M. R. (1982). Audiences' reactions to self-enhancing, selfdenigrating, and accurate self-presentations. Journal of Experimental Social Psychology, 18(1), 89-104.

SimanTov-Nachlieli, I., Har-Vardi, L., \& Moran, S. (2020). When negotiators with honest reputations are less (and more) likely to be deceived. Organizational Behavior and Human Decision Processes, 157, 68-84.

Somerville, P. (2009). The feeling's mutual': Respect as the basis for cooperative interaction. Securing respect: Behavioural expectations and anti-social behaviour in the UK, 139-167. The Policy Press.

Stukas, A. A. \& Snyder, M. (2016). Self-fulfilling prophecies. In Friedman, H. (Ed.) Handbook of mental health, Vol. 4. Elsevier, Inc.

Swami, V., \& Furnham, A. (2007). Unattractive, promiscuous and heavy drinkers: Perceptions of women with tattoos. Body Image, 4(4), 343-352.

Wildschut, T., Pinter, B., Vevea, J. L., Insko, C. A., \& Schopler, J. (2003). Beyond the group mind: a quantitative review of the interindividual-intergroup discontinuity effect. Psychological Bulletin, 129(5), 698-722.

Wilkinson, P. (2011, October 18). Why Israelis believe one soldier is worth 1,000 Palestinian prisoners. Retrieved from http://www.cnn.com/2011/10/17/world/meast/israel-prisonerswap-explainer/index.html

Wojciszke, B., Bazinska, R., \& Jaworski, M. (1998). On the dominance of moral categories in impression formation. Personality and Social Psychology Bulletin, 24(12), 1251-1263.

Wolf, R. (2011). Respect and disrespect in international politics: The significance of status recognition. International Theory, 3(1), 105-142.

Yeini, S. A. (2018). Weighing lives: Israel's prisoner-exchange policy and the right to life. Minn. J. Int'l L., 27, 493-526. 